\title{
A circulação de práticas antirracistas na web e na escola básica: encontros de esperança
}

\section{Lêda Maria Vieira Boaventura}

Universidade Federal do Rio de Janeiro - UFRJ

Secretaria Municipal de Educação da Cidade do Rio de Janeiro - SME/RJ

\begin{abstract}
Resumo
Baseada na visão de que usamos a linguagem para agir no mundo, focalizo o uso de textos da internet no contexto escolar para fomentar práticas reflexivas e antirracistas. Neste artigo, o principal evento discursivo é a respeito da história de superação da judoca Rafaela Silva, medalhista de ouro nos Jogos Olímpicos Rio-2016, que impulsionou atividades de valorização das performances negras ao longo do ano letivo. Chamo de encontros de esperança, os letramentos contemporâneos, especialmente o Grupo de Estudos Performances Negras em Foco, pois nós acreditamos que os processos de partilha de ideias e práticas que têm foco na circulação de outras histórias sobre as pessoas negras em nossa escola, podem desestabilizar discursos racistas e essencialistas que circulam em nossa sociedade.
\end{abstract}

Palavras-chave: Letramentos. Internet. Educação Antirracista.

\begin{abstract}
Based on the view that we use language to act in the world, I focus on the use of texts from the internet at school in order to develop reflexive and anti-racist practices. The main discursive event in this paper is about Rafaela Silva, gold medalist in the Rio-2016 Olympic Games, whose story of overcoming obstacles fostered activities to value black performances over the course of the school year. I call meetings of hope the contemporary literacies, especially the Black Performances at Issue Study Group, because we believe that the process of sharing ideas and activities that focus on the circulation of other stories about black people in our school may undermine racist and essentialist discourses which circulate in our society.

Key words: Literacies. Internet. Anti-racist Education.
\end{abstract}

\section{INTRODUÇÃO}

O modo de se relacionar socialmente tem mudado na contemporaneidade, notadamente em razão da popularização das novas tecnologias da informação e da comunicação. Se antes, as redes de conversas sobre textos precisavam de espaços físicos para acontecer, hoje, basta um clique de compartilhamento para fazer um texto viajar por quilômetros. Basta uma curtida para incitar discussões quentíssimas. Desse modo, a extraordinária intensidade da circulação textual no tempo presente tem alterado 
substancialmente a natureza das interações sociais e as relações de força entre diferentes subjetividades e coletividades.

As práticas de cunho racista em nosso país, por exemplo, têm sido abordadas nas redes sociais, pela mídia e pelos intelectuais com maior frequência devido à crescente percepção da dinâmica dos processos discriminatórios que permeiam a nossa sociedade, como fruto dessa intensa circulação textual promovida pela internet nos últimos anos, dos avanços na luta do Movimento Negro (D’ADESKY, 2005), do fortalecimento de coletivos de mulheres negras como Meninas Black Power, de movimentos como a Marcha das Mulheres Negras e de um momento de intensa e constante reflexão sobre as formas de sociabilidade.

\footnotetext{
Embora escondida atrás da fachada da miscigenação, a cultura racista se encontra virtualmente em todas as interações sociais entre brancos, pardos e pretos. É com base em uma rede de crenças que posições subordinadas são consideradas o local apropriado para pardos e pretos e que espaços sociais que envolvem controle e acesso a recursos devem ser ocupados por brancos (TELLES, 2003, p. 310).
}

Tradicionalmente, tínhamos o hábito de silenciar as ofensas a pretas/os e pardas/os baseadas nessa "rede de crenças" que Telles menciona. Esse silêncio sempre escondeu a dura face do racismo à brasileira (TELLES, 2003), por esse motivo, Cavalleiro (2001) assevera a relevância de pensarmos em uma educação antirracista em nosso país. Nas escolas, por exemplo, palavras racistas proferidas pelas/os alunas/os foram por longos anos silenciadas pelas/os professoras/es para evitar polêmicas na sala de aula. Hoje, contudo, injúrias raciais são divulgadas, comentadas e criticadas na internet com muita frequência, o que tem mostrado o teor do nosso racismo e dado maior visibilidade aos debates sobre o tema. Nesse mesmo contexto, circulam a indignação com o racismo, os processos de construção das subjetividades negras de modo afirmativo e a estruturação de coletivos com encontros online e offline. A dinâmica nas redes sociais tem nos mostrado como pessoas diferentes tem se unido para lutar por causas comuns. 


\section{RAFAELA SILVA: EXEMPLO DE SUPERAÇÃO E SUCESSO}

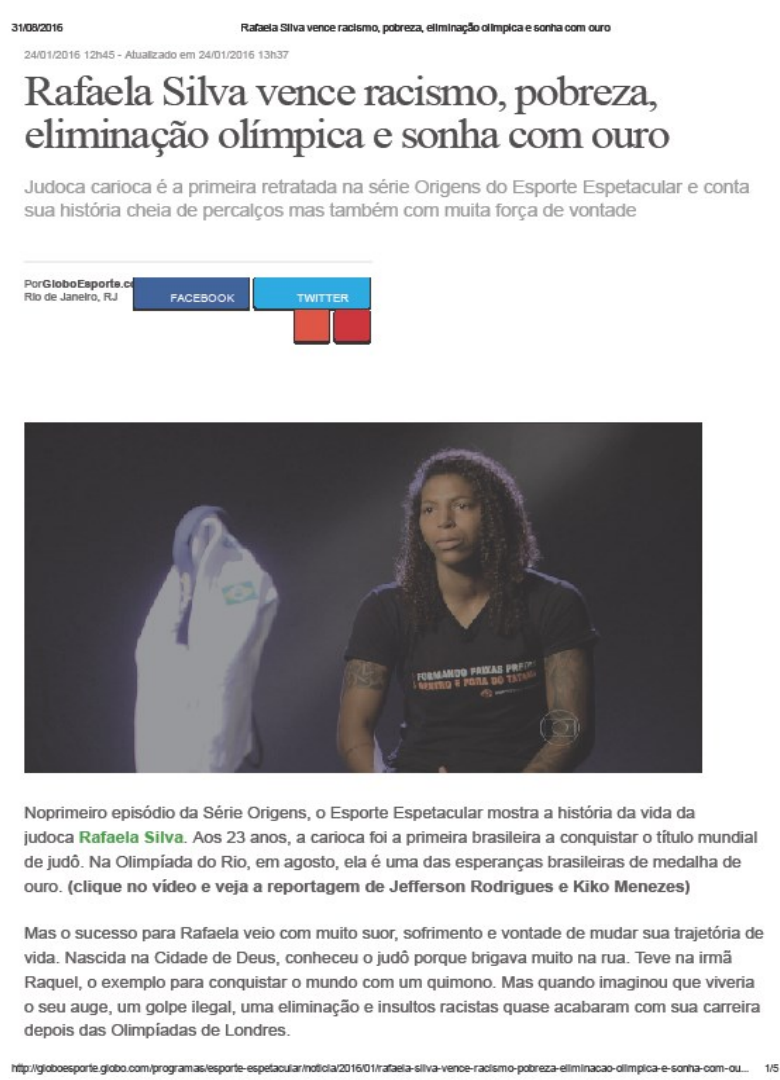

FIGURA 1

Internet

Rafaela Silva, medalhista de ouro nos Jogos Olímpicos Rio - 2016, passou a ser uma referência para as crianças de uma escola da rede municipal em um bairro da zona oeste do Rio de Janeiro, tornando-se um modelo de superação e sucesso. A judoca brasileira, que nasceu na Cidade de Deus, Rio de Janeiro, frequentou as primeiras aulas de judô no Instituto Reação, organização não governamental idealizada pelo medalhista olímpico Flavio Canto (FIGURA 1) ${ }^{1}$. A unidade do Instituto Reação frequentada por Rafaela fica dentro da Cidade de Deus e atende ainda hoje as crianças da região. A atleta participou de vários campeonatos mundiais até chegar aos jogos olímpicos de Londres, em 2012. Na ocasião, Rafaela cometeu um erro na luta em etapa eliminatória, foi desclassificada e quando pegou o seu celular em busca de algum apoio (como declarou em entrevista), sofreu ofensas racistas (FIGURA 2).

1 http://globoesporte.globo.com/programas/esporte-espetacular/noticia/2016/01/rafaelasilva-vence-racismo-pobreza-eliminacao-olimpica-e-sonha-com-ouro.html. 


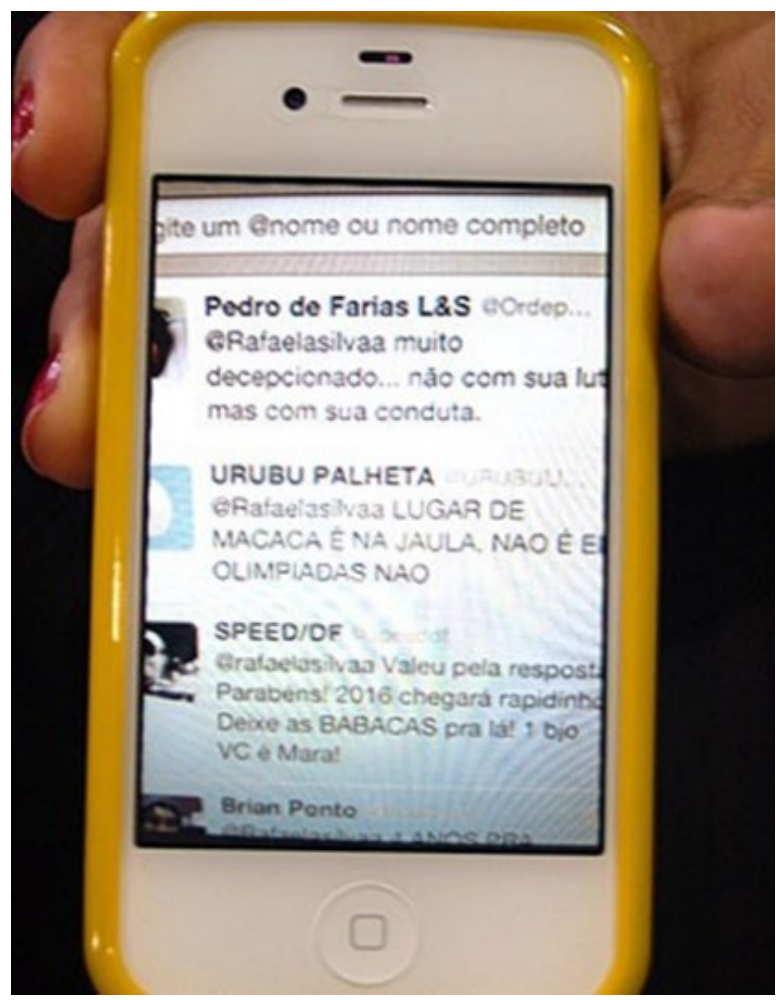

FIGURA 2

Internet

Há muitas reportagens disponíveis na web a respeito da história de superação da atleta e conquista da medalha de ouro em 2016, seguidas de incontáveis comentários: "Rafaela desabafa: 'O macaco que tinha que estar na jaula hoje é campeão"" ; "Brazilian Rafaela Silva almost quit judo because of racism. Now she's an Olympic gold medalist"3, são alguns exemplos.

De acordo com a reportagem do programa Esporte Espetacular (FIGURA 1), após as ofensas de 2012, Rafaela Silva demorou a sair de casa, voltar a treinar e quis desistir do esporte. Somente com o apoio de uma psicóloga a atleta pode retornar aos treinos e seguir para outros campeonatos até chegar às olimpíadas em 2016 (FIGURA 3).

\footnotetext{
${ }^{2}$ http://olimpiadas.uol.com.br/noticias/redacao/2016/08/08/aos-prantos-rafaela-desabafa me-disseram-que-eu-era-uma-vergonha.htm

${ }^{3}$ https://www.washingtonpost.com/news/early-lead/wp/2016/08/08/brazilian-rafaela silva-almost-quit-judo-because-of-racism-now-shes-an-olympic-gold-medalist/
} 


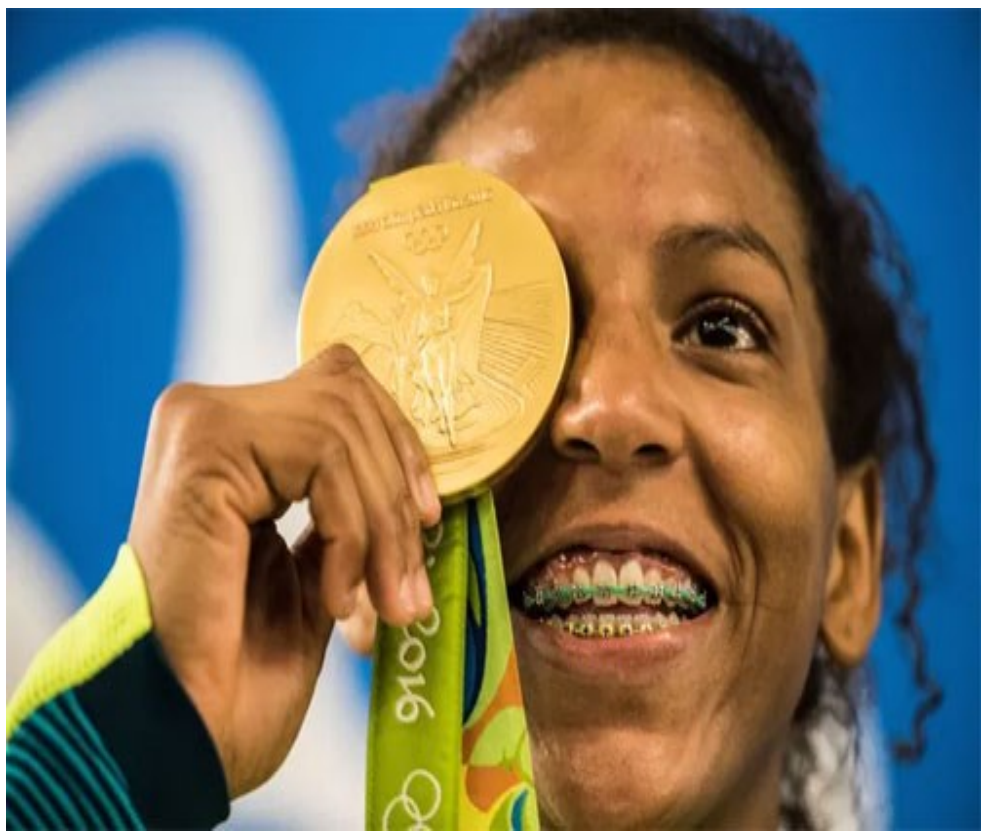

FIGURA 3

Internet

A repulsa aos enunciados racistas contra mulheres negras, difundidos na internet, nos impulsionam ao engajamento em práticas de letramento outras com o objetivo de contar outras histórias sobre as/os negras/os, rompendo com os significados tradicionalmente fixados pelas práticas discursivas racistas.

Histórias importam. Muitas histórias importam. Histórias têm sido usadas para expropriar e caluniar. Mas, histórias podem também ser usadas para empoderar e humanizar. Histórias podem destruir a dignidade de um povo, mas histórias também podem reparar essa dignidade perdida. (ADICHIE, 2009/conferência)

Esses letramentos outros estão em transcurso em coletivos de valorização da cultura negra, nos parques, nas escolas, nos bairros e favelas, em associações de moradores ou grupos nas redes sociais. Mas, tenho como foco o processamento desses letramentos na escola. Tenho disponibilizado, portanto, no ensino básico, no qual atuo como professora, algumas práticas de letramento que têm desafiado os modos tradicionais de atribuir sentido às negritudes.

E como seria, então, a circulação desses letramentos na escola? No terreno do letramento autônomo, no espaço da aprendizagem neutra e desconectada da vida social, o que significa permitir "ser transformado" por sistemas de letramentos outros? Chamo de outros não apenas porque fluem em outros espaços, neste caso na internet, mas porque se processam em outras bases, com dinâmicas outras e com objetivos outros, que não o de letrar - ensinar a letra para o repasse de ideias e conteúdos. De 
acordo com Adichie (2009) as histórias que contamos são cruciais na construção de quem somos, sendo assim, está proposta a circulação de outras histórias sobre negras e negros na escola básica.

\section{LETRAMENTOS OUTROS NO CHÃO DA ESCOLA}

O conservadorismo da instituição escolar, especialmente nos anos iniciais da educação básica, mantém muitas/os docentes apegadas/os ao modelo autônomo de letramento, que se caracteriza, entre outros aspectos, por entender a letra como um instrumento transparente de repasse de ideias, pela suposta neutralidade, objetividade e isenção contextual dos textos (STREET, 1995) e que restringe a entrada de outras práticas de letramento nesse espaço.

Pode-se afirmar que a escola, a mais importante das agências de letramento, preocupa-se, não com o letramento, prática social, mas com apenas um tipo de prática de letramento, a alfabetização, o processo de aquisição de códigos [...] (KLEIMAN, 1995, p. 20)

A escola, historicamente, privilegia a noção de linguagem como representação do real ancorada na perspectiva moderna/ cartesiana e nega o caráter ideológico e cultural da interpretação ou representação dos objetos, que são compreendidos como dados na natureza. Street (2009) distingue o letramento autônomo, que dissimula aspectos culturais e ideológicos para se apresentar como um modelo neutro e universal, de letramento ideológico, que compreende letramento como uma prática social baseada em princípios epistêmicos, constituídos sócio-historicamente e permeados por relações assimétricas. $\mathrm{O}$ autor entende que operar com uma dessas perspectivas tem implicações para a pesquisa e para a prática.

[...] o modelo ideológico de letramento oferece uma visão mais culturalmente sensível das práticas de letramento quando elas variam de um contexto para outro. Esse modelo parte de premissas diferentes das do modelo autônomo: ele postula que o letramento é uma prática social, não simplesmente uma habilidade técnica e neutra; que é sempre alicerçada em princípios epistemológicos socialmente construídos. (STREET, 2009, p.337)

A partir do modelo ideológico, muitos estudos passaram a considerar como relevante aquilo que conta como significado e letramento em contextos sociais específicos, ao invés de simplesmente impor um modelo de letramento. No estudo desses contextos é indispensável manter a sensibilidade etnográfica para a compreensão 
das práticas locais, de diferentes formas de comunicação e, ao mesmo tempo, criar distanciamento dessas para situá-las em escalas sociais mais amplas (STREET, 2009).

Mas, se a escola ainda é o lugar da repetição, transmissão de conteúdos e exaltação de apenas um tipo de letramento - a alfabetização - como ela pode ser, ao mesmo tempo, lugar de esperança de circulação de textos digitais para desestabilizar discursos que oprimem mulheres negras?

É fato que, na contemporaneidade, os letramentos digitais atropelam o letramento escolar e colocam em xeque a sua importância, porque muitas lições são ensinadas e aprendidas, por assim dizer, na internet. Os encontros nas redes tornaram-se parte significativa da vida cotidiana de consideráveis contingentes populacionais na era da globalização recente. Circulam intensamente nas redes as novas sociabilidades, incluindo novas estéticas, novos modos de organização familiar, etc., o que tem afetado o perfil do alunado e professorado, impulsionando a escola a mudar, a se abrir para práticas de letramento complexas, que mesclam a cultura digital e a cultura escolar. Há, portanto, uma expansão dos letramentos. Não há mais "o letramento", mas, letramentos, no plural, em franca expansão na era da revolução digital.

\section{O GRUPO DE ESTUDOS PERFORMANCES NEGRAS EM FOCO}

Em nossa escola, desde 2015, nos Centros de Estudos Integrais ${ }^{4}$, ocorrem as reuniões oficiais do Grupo de Estudos Performances Negras em Foco. Nesses encontros, práticas de valorização das identidades negras são estimuladas e as/os docentes, junto à direção e à coordenação pedagógica, compartilham as suas atividades por meio de relatos, fotos e vídeos. O principal objetivo do Grupo de Estudos é colaborar na formação de professoras pesquisadoras da própria prática para uma educação antirracista e compartilhar, discutir e estimular práticas que poderão: i) inserir personagens negras/os posicionadas/os como protagonistas e modelos de beleza no cotidiano escolar e ii) enfraquecer discursos racistas que circulam na escola e em nossa sociedade.

Uma temática que tem norteado as intervenções no Grupo de Estudos Performances Negras em Foco é a de como nós utilizamos a linguagem para construir

\footnotetext{
${ }^{4}$ Os Centros de Estudos Integrais são reuniões bimestrais entre as docentes e a coordenação pedagógica, que ocorrem dentro do espaço escolar. As mesmas estão previstas no calendário escolar da Secretaria Municipal de Educação da cidade do Rio de Janeiro (SME/ RJ).
} 
as realidades (MOITA LOPES, 2003). E como podemos contar histórias diferentes daquelas que ouvimos até hoje sobre o povo negro. Sabe-se que uma única história vem sendo privilegiada em nossos currículos - somente a perspectiva européia tem orientado a nossa visão de mundo - e a escritora Chimamanda Adichie (2009) aponta para os danos causados por uma única história quando essa se torna "verdade suprema", excluindo todas as outras, gerando estereótipos e discriminação.

Refletindo acerca das histórias que ganham força de verdade nas sociedades, Adichie ressalta a questão das relações de poder (FOUCAULT, 2006):

Como são contadas, quem as conta, quando e quantas histórias são contadas, tudo realmente depende do poder. Poder é a habilidade de não só contar a história de uma outra pessoa, mas de fazê-la a história definitiva daquela pessoa. (ADICHIE, 2009, p.20)

Objetivamos, portanto, tematizar a relevância do uso da linguagem na sociedade e a força política das histórias que contamos. A proposta central é convidar a nossa escola a contar outras histórias sobre quem são as negras e os negros na vida social, por meio da construção dessas e desses como protagonistas e modelos de beleza.

\section{LETRAMENTOS CONTEMPORÂNEOS: ENCONTROS DE ESPERANÇA}

A colonialidade do poder estabeleceu sistemas classificatórios centrados na Europa e transformou histórias locais européias em narrativas universais, ou seja, em projetos globais. Contudo, na contemporaneidade, essas histórias universais cada vez mais perdem força e credibilidade. De acordo com Mignolo (2003, p. 47):

\footnotetext{
O neoliberalismo, com sua ênfase no mercado e no consumo, não é apenas uma questão econômica, mas uma forma de civilização. A atual impossibilidade ou falta de credibilidade de histórias universais ou mundiais não é postulada por uma teoria pós-moderna, mas pelas forças econômicas e sociais a que geralmente nos referimos como globalização e pela emergência de formas de conhecimento que foram subalternizadas nos últimos quinhentos anos, dentro dos projetos globais mencionados [...]
}

Essas formas de conhecimento, silenciadas pela modernidade, emergem agora como novos loci de enunciação, de histórias e práticas de letramento que se chocam, rivalizam com os discursos hegemônicos construídos nas regiões centrais do sistema colonial moderno (ibdem). Esses novos loci de enunciação são descritos como gnose liminar: 
A "gnose liminar" é a razão subalterna lutando para colocar em primeiro plano a força e a criatividade de saberes, subalternizados durante um longo processo de colonização do planeta que foi, simultaneamente, o processo através do qual se construíram a modernidade e a razão moderna. (ibdem, p. 36)

A gnose liminar rompe com a perspectiva da territorialização do conhecimento e vai operar sob lógicas nômades, fronteiriças e liminares, envolvendo intensos e contínuos entrecruzamentos de fronteiras, circulação de textos, ideias, saberes e fazeres, desmantelando barreiras entre territórios de conhecimento, desestabilizando hierarquias e inaugurando outras formas de se constituir nas relações sociais. $\mathrm{Na}$ era digital, com as múltiplas redes de relacionamento virtual, essas fronteiras se dissolvem ainda mais rapidamente e os significados locais mais subalternizados pela era moderna, circulam intensamente, podendo fluir com status de significado global. Múltiplas histórias locais hoje se organizam em redes na construção de macronarrativas que se contrapõem às formas hegemônicas do conhecimento da epistemologia moderna pós século XVIII (ibdem).

Os letramentos contemporâneos devem ser pensados desse lugar de fronteira, ou seja, são os letramentos dos encontros - encontros entre as práticas da cultura digital e as práticas da cultura escolar. Encontros entre práticas subalternizadas e práticas hegemônicas, com intenso embate e disputa por território (muito mais fluido e fugaz), por valorização, por hegemonia, sempre em práticas situadas perpassadas por relações de poder.

As práticas de letramento são centrais para os processos de mudança social. Somente a comunicabilidade possibilita aos indivíduos gerarem processos de reflexividade que incitem pensar em outras sociabilidades. As ações políticas dependem, portanto, de redes de encontro entre sujeitos "comunicativos, cooperativos e articulados" (HARDT E NEGRI, 2005, p. 169). No campo da educação, Cope e Kalantzis (2000) asseveram que ser letrado significa se tornar participante ativo nas mudanças sociais e na construção de novos futuros. Na escola municipal na qual atuo, tenho proposto práticas de encontro, nas quais tornou-se central a circulação de textos da internet, como os que cito neste trabalho.

Sendo assim, com o objetivo de encorajar as docentes a se engajarem nas discussões e atividades antirracistas, decidi compartilhar em uma de nossas reuniões um episódio que deixasse mais evidente o teor das ofensas racistas proferidas às pessoas 
negras em nossa sociedade. Projetei a reportagem do programa Esporte Espetacular que conta a trajetória de Rafaela Silva desde a infância na Cidade de Deus (FIGURA 1) e chamei a atenção para os danos que o racismo causou à atleta, para que então, pudéssemos pensar na importância do tema, rompendo com o silêncio acerca da questão e avançando com práticas pedagógicas antirracistas. Uma das atividades incluiu a visita da boneca que construímos para representar Rafaela Silva, a construção de relações de afeto com a mesma e a produção de ilustrações da atleta (FIGURAS 4, 5 e 6).

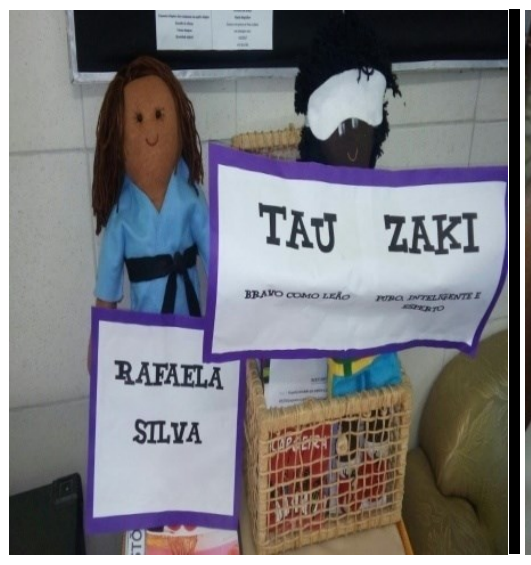

FIGURA 4

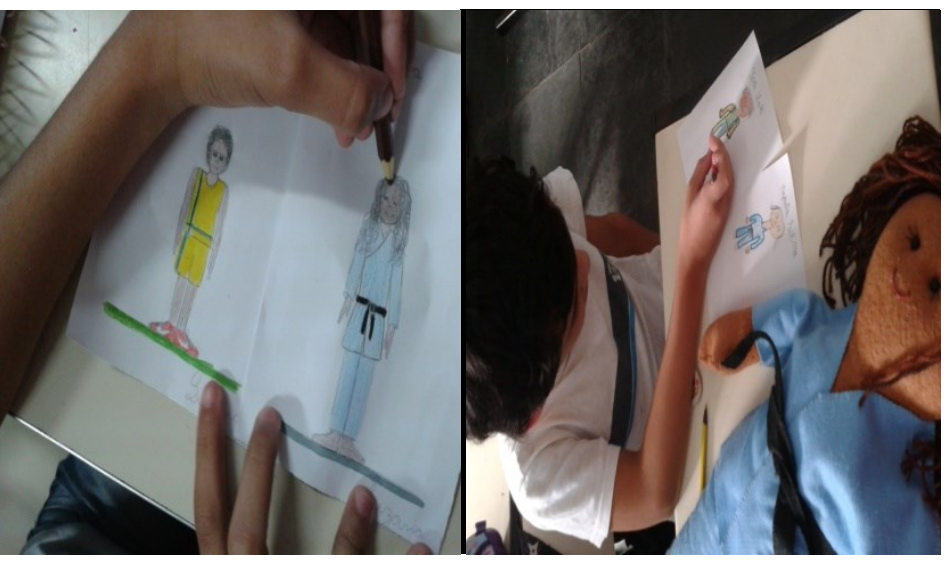

FIGURA 5
FIGURA 6

Arquivo da escola

Pensando na importância e nos efeitos da trajetória dos textos que circulam na internet, recorro a Blommaert (2007), que aponta que os textos quando viajam de um lugar para o outro mudam sua função e seu valor semiótico. Assim, em práticas de letramento de fronteira ${ }^{5}$, as viagens textuais ocorrem com frequência e viabilizam processos de recontextualização contínua dos enunciados. O autor assevera que, em tempos de globalização da informação, não estamos alheios aos significados que circulam em outras escalas. Estamos o tempo inteiro em movimento e sendo bombardeados por uma profusão desordenada de textos, o que muitas vezes gera instabilidade e insegurança, devido ao fato de não haver mais formas únicas e amarradas de existência social. Essa dinâmica mobilidade de significados entre diversos contextos espaço-temporais é permeada por relações assimétricas entre pessoas e seus repertórios

\footnotetext{
${ }^{5} \mathrm{O}$ termo letramento de fronteira está fundamentado no conceito de gnose liminar de Mignolo (2003), que compreende que a produção do conhecimento consiste no entrecruzamento de práticas de significação diversas. Assim, me aproprio dessa ideia fronteiriça, na qual letramentos se chocam e se afetam mutuamente, resultando em letramentos outros (não-hegemônicos) para pensar nos efeitos resultantes da interação entre os significados (por vezes conflitantes) que circulam na escola e nos ambientes digitais para promover práticas de letramento desafiadoras e antirracistas.
} 
sociolinguísticos (Blommaert, 2007, p.8), pois cada espaço-tempo é perpassado por regimes de letramento que estabelecem critérios de estratificação e distinção para diversos recursos semióticos, definindo como os mesmos podem ser expressos, quem pode empregá-los e em que circunstâncias (ibdem, p.9).

Entretanto, essa intensa circulação e friç̧ão de textos também gera incertezas e produz desestabilizações sobre os regimes de verdade cristalizados pela tradição moderna. Sob essa perspectiva, o choque permanente entre diferentes práticas de letramento e distintas subjetividades - marca indelével da globalização recente pode abrir espaço para a reconfiguração de significados engessados em específicos contextos e seus regimes de letramento e fomentar práticas mais solidárias e democráticas de reinvenção da vida social.

Hardt e Negri apontam que uma das faces da globalização "é a criação de novos circuitos de cooperação e colaboração que se alargam pelas nações e os continentes, facultando uma quantidade infinita de encontros" (2005, p. 12). Nesses encontros residem as forças da comunicabilidade, cooperação e articulação proporcionada pelas práticas de letramento que neles se constroem. Neles, a multidão se encontra e "uma multiplicidade social [é] capaz de se comunicar e agir em comum, ao mesmo tempo em que se mantém internamente diferente" (ibdem, p.13). Assim, os autores chamam a atenção para a centralidade do uso da linguagem apontando que "na realidade, a contradição entre hierarquias linguísticas e produção e partilha linguísticas é o que torna hoje a linguagem um ponto tão poderoso de conflito e resistência."

A linguagem pode ser usada para criar e sustentar relações de controle, mas é ela também que possibilita aos subalternizados a transformação criativa de suas realidades. Podemos dizer que "todos os elementos ativos da sociedade são agentes de criatividade linguística (grifo meu) na constante geração de linguagens comuns" (ibdem, p. 179), sendo potencialmente agentes ativos na desestabilização de hierarquias e articuladores de resistências e mudança social. Sendo assim, há esperança nas ações coletivas da multidão. As redes sociais, por exemplo, são consideradas espaços de letramento nos quais há intensa criatividade linguística e a criação de coletivos e redes de solidariedade contra o racismo e de construção das subjetividades negras em outras bases.

Nos espaços-tempo institucionais e não-institucionais, essas práticas de letramento favorecem a construção de redes de apoio e de conhecimentos comuns. 
Compreendendo letramento como o lugar social no qual as pessoas agem no mundo usando a linguagem, as práticas nesses grupos apontam para uma nova política de vida. Podemos chamar esses encontros de práticas de letramentos de microresistência. Esses encontros reforçam outros modos de ver o mundo em práticas de letramento em redes, especialmente rompendo com os padrões do que é um letramento legítimo, sob uma perspectiva tradicional.

Na luta antirracista, a criação de hashtags (\#) tornou-se uma marca nas redes sociais, pois diante de manifestações racistas, a multidão se reúne para apoiar a pessoa que sofreu a ofensa racista e demonstrar indignação com o ato injurioso. Nessas hashtags, muitas vezes, o próprio enunciado injurioso já é reapropriado de modo afirmativo, como nos ensinou Butler (1997). A hashtag \#somostodosrafaelasilva (FIGURAS 7 e 8) foi lançada em apoio à atleta durante os jogos olímpicos de Londres (2012) após a divulgação das ofensas racistas proferidas contra ela no twitter (FIGURA 2). Assim, laços de solidariedade são frequentemente construídos entre pessoas completamente diferentes entre si, demonstrando que na atualidade, a construção de redes de apoio não depende da união de pessoas iguais (FIGURAS 9 e 10).

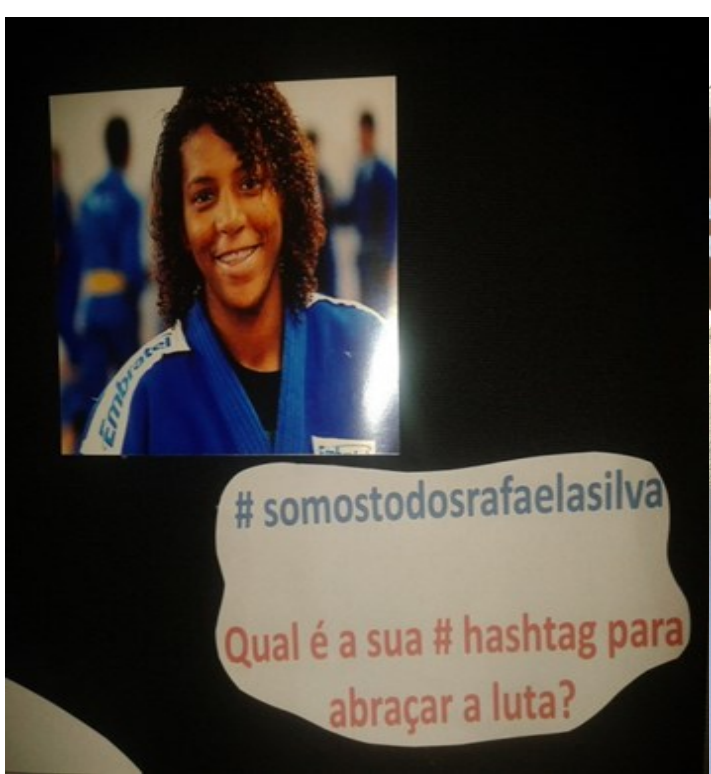

FIGURA 7

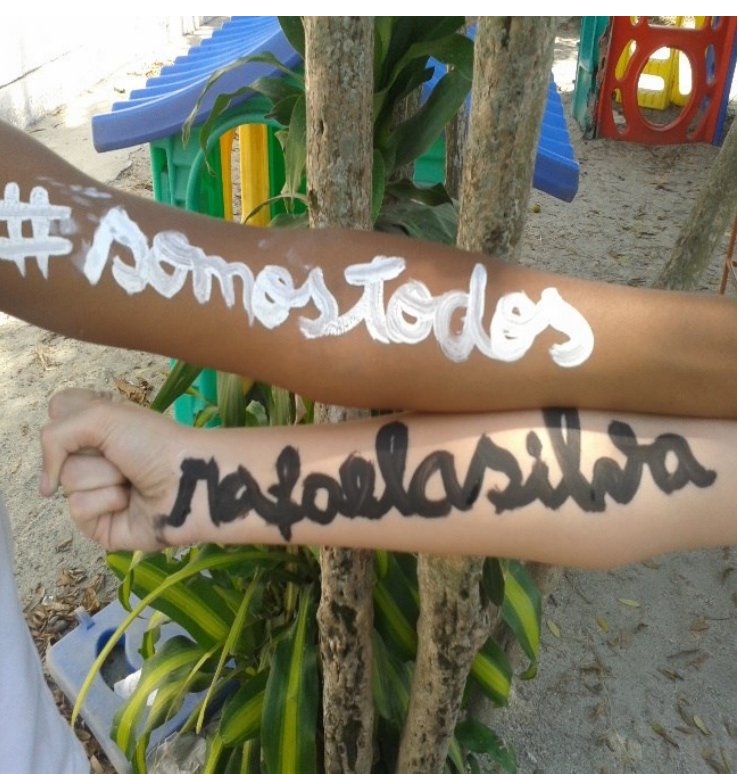

FIGURA 8 


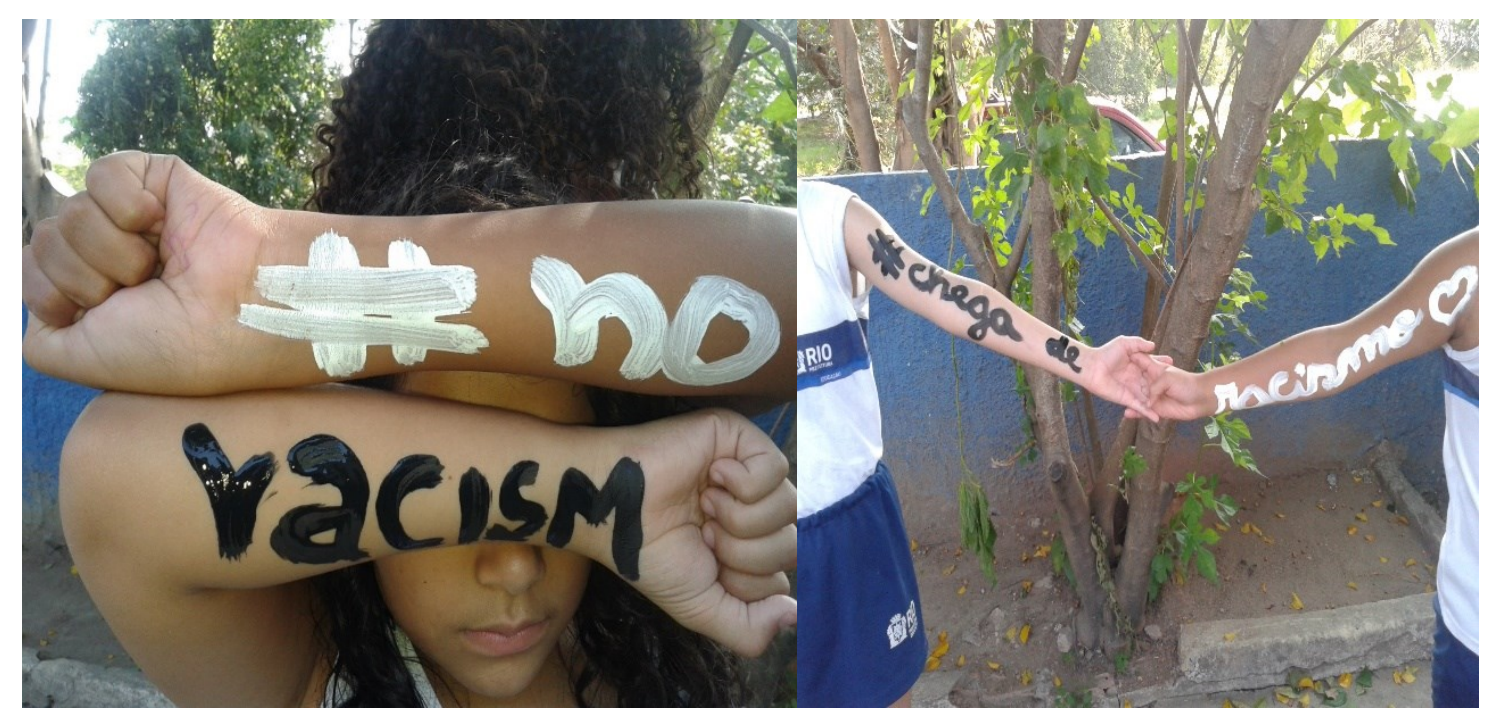

FIGURA 9

FIGURA 10

Em nosso contexto, por exemplo, educadoras com formações completamente distintas dentro da instituição escolar têm o objetivo comum de promover e compartilhar atividades que possibilitem a construção das subjetividades negras de modo positivo, rompendo com os discursos da escravidão e democracia racial. Temos deixado fluir em nossos diálogos e atividades os textos que circulam em outras práticas de letramento, como na internet e nas ruas, construindo um letramento translocal, de fronteira, dentro de uma instituição historicamente reprodutora da lógica do letramento autônomo. Temos inserido personagens negras/os posicionadas/os como protagonistas, como foi o caso da Rafaela Silva, no cotidiano escolar com o objetivo de enfraquecer e desestabilizar discursos racistas que circulam na escola e em nossa sociedade, porque contar outras histórias (ADICHIE, 2009), ou seja, usar a linguagem para nos reinventar, nos enche de esperança em futuros melhores (MOITA LOPES, 2013).

\section{CONSIDERAÇÕES FINAIS}

Ressaltei neste ensaio a relevância dos textos digitais para a desestabilização das práticas escolares tradicionais, especialmente para o fim do silêncio escolar acerca da temática racial, pois as denúncias de discriminação racial que circulam na internet impulsionam ainda mais a luta antirracista e fortalecem práticas afirmativas em diversos contextos. 
A escolha de textos sobre a judoca Rafaela Silva para compartilhar com as docentes nos encontros do Grupo de Estudos Performances Negras em Foco e para elaborar atividades para as crianças de nossa escola foi instigada pela pesquisa sobre atletas negras que participariam dos Jogos Olímpicos Rio - 2016. Creio que contar histórias como a de Rafaela na escola favorece o entrecruzamento entre diferentes práticas de letramento produzindo processos de reflexividade e convidando as pessoas a pensar em outros modos de construção de subjetividades.

Atentei para a noção de que nós usamos a linguagem para agir no mundo, contando histórias e construindo realidades que nos posicionam e posicionam os outros na vida social. Se por um lado, as histórias que contamos podem sustentar relações de controle e oprimir determinados grupos, por outro, nós podemos contar outras histórias reposicionando esses grupos como protagonistas.

Sendo assim, o uso criativo da linguagem pode produzir desestabilizações provisórias que provocam efeitos de mudança nas relações sociais, nas crenças e nas práticas. Os letramentos contemporâneos são espaços de esperança, porque são compreendidos como lugar de encontros entre cosmologias distintas, conflituosas, que geram processos de reflexividade, criatividade linguística e possibilitam pensar em outros modos de se constituir socialmente, desestabilizando discursos que oprimem as mulheres negras, por exemplo, proporcionando engajamento político, mudanças epistemológicas, construção de redes de solidariedade e cooperação.

Ressalto a importância de reuniões de partilha de ideias e práticas docentes como as que ocorrem no Grupo de Estudos Performances Negras em Foco - que são encontros de esperança - por mesclarem formas diversas de construir significado (dialogando com textos digitais e práticas subalternizadas). Esses encontros têm colaborado na construção de parcerias não só de pensamento, mas de ações e podem apontar alguns caminhos para a estruturação de uma educação antirracista na educação básica chamando a atenção, sobretudo, para a centralidade da linguagem nas relações sociais. 


\section{REFERÊNCIAS}

ADICHIE, Chimamanda Ngozi. The Danger of a Single Story. TED Global Conference $2009 . \quad$ Disponível em http://www.ted.com/talks/chimamanda_adichie the_danger_of_a single_story.

BLOMMAERT, J. Grassroots literacies. Writing, identity in Central Africa. London: Routledge, 2007.

BROCKMEIER, J. \& OLSON, D. R. The literacy episteme: from Innis to Derrida. In: OLSON, D. R. \& TORRANCE, N. (Orgs.). The Cambridge handbook of literacy. Cambridge: Cambridge University Press, 2009.

BUTLER, J. Excitable speech. On Linguistic Vulnerability. London and New York, 1997.

CAVALLEIRO, E. Educação anti-racista: compromisso indispensável para um mundo melhor. In CAVALLEIRO, E. (org.) Racismo e anti-racismo na educação.Repensando nossa escola. São Paulo: Summus, 2001.

COPE, B. \& KALANTZIS, M. Introduction: Multiliteracies: the beginning of an idea. In COPE, B \& KALANTZIS, M. (Eds.) Multiliteracies. Literacy learning and the design of social futures. Londres: Routledge, 2000.

D'ADESKY, J. Pluralismo étnico e multi-culturalismo: racismos e anti-racismos no Brasil. Rio de Janeiro: Pallas, 2005.

FOUCAULT, M. História da sexualidade I: a vontade de saber. $17^{\circ}$ edição. São Paulo: Edições Graal Ltda., 2006 [1981].

HARDT, M. \& NEGRI, A. Multidão. Rio de Janeiro: Editora Record, 2005.

KLEIMAN, A. Modelos de letramento e as práticas de alfabetização na escola. In KLEIMAN, A. Os significados do letramento. Campinas: Mercado de Letras, 1995.

MIGNOLO, W. D. Histórias locais/projetos globais: colonialidade, saberes subalternos e pensamento liminar. Belo Horizonte: Editora UFMG, 2003.

MOITA LOPES, L. P. Pesquisa em Linguística Aplicada: entre lugares/margens, discursos emergentes e políticas. Disponível no site: https://www.youtube.com/watch?v=bWFAkLwTMM8. Unicamp - II Ciclo de Diálogos em Linguística Aplicada - Instituto de Estudos da Linguagem - IEL, 2013.

- Socioconstrucionismo: discurso e identidades sociais. In:

MOITA LOPES, L. P. (Org.). Discursos e identidades. Campinas, SP: Mercado de Letras, 2003.

STREET, B. Ethnography of writing and reading. In: OLSON, D. \& TORRANCE, N. (Orgs.). Cambridge Handbook of Literacy. Cambridge: Cambridge University Press, 2009. 
Literacy practices and Literacy Myths. In STREET, B Social Literacies. Critical Approaches to Literacy in Development, Ethnography and Education. Londres: Longman, 1995.

TELLES, E. Racismo à brasileira: uma nova perspectiva sociológica. Rio de Janeiro: Relume Dumará, 2003.

\section{A AUTORA}

Lêda Maria Vieira Boaventura é professora de inglês da educação básica na Secretaria Municipal de Educação da Cidade do Rio de Janeiro, mestre em Linguística Aplicada pela Universidade Federal do Rio de Janeiro (UFRJ), especialista em Educação e Relações Raciais pela Universidade Federal Fluminense (PENESB/UFF) e doutoranda do Programa Interdisciplinar de Pós-graduação em Linguística Aplicada da UFRJ.

E-mail: ledaboaventura@rioeduca.net

ledaboaventura.lb@gmail.com 